Article

\title{
Synthesis of Narrow Molecular Weight Distribution Norbornene-Lactone Functionalized Polymers by Nitroxide-Mediated Polymerization: Candidates for 193-nm Photoresist Materials
}

\author{
Zi Jun Wang ${ }^{1}$ and Milan Maric ${ }^{2, *}$ \\ 1 Max Planck Institute for Polymer Research, Ackermannweg 10, 55128 Mainz, Germany; \\ E-Mail: zi.wang@mail.mcgill.ca \\ 2 Department of Chemical Engineering, McGill Institute of Advanced Materials (MIAM), \\ Centre for Self-Assembled Chemical Structures (CSACS), McGill University, \\ 3610 University Street, Montreal, QC H3A 0C5, Canada \\ * Author to whom correspondence should be addressed; E-Mail: milan.maric@mcgill.ca; \\ Tel.: +1-514-398-4272; Fax: +1-514-398-6678.
}

Received: 16 January 2014; in revised form: 10 February 2014 / Accepted: 17 February 2014 / Published: 21 February 2014

\begin{abstract}
One hundred ninety three-nanometer candidate photoresist materials were synthesized by nitroxide-mediated polymerization (NMP). Statistical copolymerizations of 5-methacryloyloxy-2,6-norboranecarbolactone (NLAM) with 5-10 mol\% of controlling co-monomers (which are necessary for controlled polymerizations of methacrylates by NMP with the initiator used) in the feed, such as styrene (ST), p-acetoxystyrene (AcOST), 2-vinyl naphthalene (VN) and pentafluorostyrene (PFS), using the unimolecular BlocBuilder ${ }^{\circledR}$ initiator in $35 \mathrm{wt} \%$ dioxane solution at $90{ }^{\circ} \mathrm{C}$ were performed. As little as $5 \mathrm{~mol} \%$ controlling comonomer in the feed was demonstrated to be sufficient to lead to linear evolution of number average molecular weight $\bar{M}_{n}$ with respect to conversion up to $50 \%$, and the resulting copolymers had dispersities $\bar{M}_{w} / \bar{M}_{n}$ of $\sim 1.3$ in most cases, an attractive feature for reducing line width roughness (LWR) in photoresists. The copolymers generally showed relatively low absorbance at $193 \mathrm{~nm}$, comparable to other 193-nm candidate photoresists reported previously, despite the inclusion of a small amount of the styrenic co-monomers in the copolymer.
\end{abstract}


Keywords: nitroxide-mediated polymerization; copolymerization; 193-nm photoresists

\section{Introduction}

Nitroxide-mediated polymerization (NMP), a type of controlled radical polymerization (CRP), combines the practicality of conventional free radical polymerization with the good microstructural control usually associated with living polymerizations, like ionic polymerization [1,2]. Traditionally, NMP mediated by TEMPO (2,2,6,6-tetramethylpiperidine- $N$-oxyl) was limited to the polymerization of styrenics only [3,4]. The development of the TIPNO (2,2,5-trimethyl-4-phenyl-3-azahexane nitroxide) and the SG1 ( $N$-tert-butyl- $N$-(1-diethylphosphono-2,2-dimethylpropyl) nitroxide) families of nitroxides subsequently extended the ability of NMP to polymerize acrylic monomers [5-7] and acrylamides [8-10]. The successful control of methacrylates with SG1 was not achieved until Nicolas et al. demonstrated that with a small amount of styrene or acrylonitrile as the controlling co-monomer, the polymerization of methyl methacrylate (MMA) could be effectively controlled with relatively low dispersity and the ability to re-initiate a second batch of monomer [11-13]. Following this, NMP has been shown to be an effective and robust method for the synthesis of a variety of poly(methacrylate)s with a small amount of controlling co-monomers, such as styrene [14,15], 9-(4-vinylbenzyl)-9H-carbazole (VBK) [16], sodium 4-styrene sulfonate [17] and 2-vinylpyridine (2VP) [18] using the SG1-based BlocBuilder unimolecular initiator. Furthermore, NMP is able to provide tight control over the molecular weight distribution and excellent retention of chain end fidelity in bulk [9,19], aqueous (mini)emulsion [20-22] and ionic liquids [23,24]. In addition, the general applicability of NMP to design polymers with complex molecular architectures has also been demonstrated by the synthesis of hyperbranched polymers [25,26], star-shaped polymers [27-29], amphiphilic block copolymers [30,31] and graft copolymers [32-34]. It should also be noted here that the thermally-induced NMP was the route chosen for the materials. Photo-NMP is another route towards homo poly(methacrylates) that is advantageous in terms of energy (lower polymerization temperatures are possible) and for absorption properties (with no styrenic required, absorption problems could potentially be avoided) [35].

The miniaturization of electronic devices using lithography requires the design of functional polymers with well-defined molecular properties. For example, polymers are often used as photoresists to imprint desired patterns onto a substrate. Two CRP techniques, such as atom transfer radical polymerization (ATRP) [36-39] and reversible addition fragmentation chain transfer (RAFT) [40-42], have been used in the past to synthesize well-defined statistical copolymers with narrow molecular weight distribution for photoresists. Parameters that characterize pattern resolution, such as the line edge roughness (LER) and line width roughness (LWR), are influenced by physical/chemical properties, such as molecular weight, dispersity, composition and microstructure [41,43-46]. However, one drawback that makes ATRP and RAFT undesirable for photoresist materials is the requirement of metal catalysts and the chain transfer agents, respectively $[42,45]$, which cause undesirable coloration, pungent odor and have to be removed through additional purification steps in order to meet the high purity standards used in the microelectronic industry. Indeed, the electronic/optical materials generally demand the 
metallic catalyst concentration to be below 1 ppm to avoid unfavorable photochemical effects $[47,48]$. Many studies have investigated the adverse effect of metallic contamination in photoresists on the lithography process and developed methods to limit the concentration to levels as low as $10 \mathrm{ppm}$ [49-52].

In general, there are three basic requirements that all 193-nm (the current standard wavelength in the photolithography industry) resists have to satisfy: high optical transparency at $193 \mathrm{~nm}$, good etch resistance and thermal stability to withstand high temperature processing conditions that are used in manufacturing [53,54]. Due to their high carbon contents, polymers with alicyclic units, such as the adamantyl and isobornyl groups, have been shown to have high etching durability [55,56]. Hydrophilic substituents, such as the hydroxyl, ester, acetate or gamma-butyrolactone groups, were also introduced to enhance the adhesion and solubility properties of the resists [57]. To further improve the etch resistance ability of the lactone structure, the addition of norbornene lactone, oxatricyclodecanone and adamantyl lactone structures have proven to be highly effective [57-59]. One representative of this class of monomers is 5-methacryloyloxy-2,6-norboranecarbolactone (NLAM). Recently, Miyazaki et al. studied the synthesis of poly(NLAM) by ATRP [37]. To the best of our knowledge, there have been no reports on the polymerization of NLAM by NMP. Thus, in this study, we report the first preparation of well-defined NLAM-rich random copolymers by NMP using BlocBuilder ${ }^{\circledR}$ as the initiator (Scheme 1). Specifically, the copolymerization kinetics of NLAM with different controlling comonomers, i.e., p-acetoxystyrene (AcOST), styrene (ST), 2-vinyl naphthalene (VN) and pentafluorostyrene (PFS), was investigated, and the absorption properties of the NLAM-rich copolymers were studied. This latter part is essential, as the methacrylate requires a controlling co-monomer for BlocBuilder-mediated NMP, which is often a styrenic, which can absorb at wavelengths near $193 \mathrm{~nm}$. The absorption tests will show which co-monomer absorbs the least and/or show what kind of co-monomer content can be tolerated. Thus, this study will suggest the feasibility of NMP-synthesized materials as potential candidates for 193-nm photoresists.

Scheme 1. The initiator BlocBuilder $^{\circledR}$ in equilibrium with free nitroxide SG1 (tert-butyl[1-(diethoxyphosphoryl)-2,2-dimethylpropyl]amino\} nitroxide).

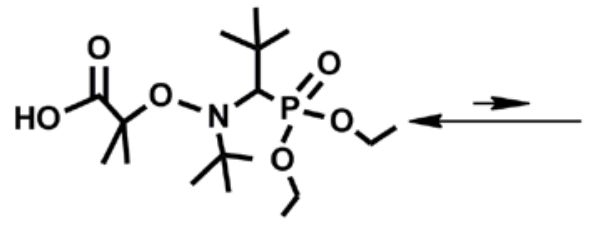

BlocBuilder

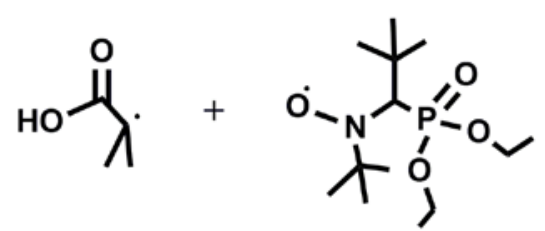

SG1 free nitroxide

\section{Experimental Section}

\subsection{Materials}

Calcium hydride (90\%-95\% reagent) and basic alumina (Brockmann, Type 1, 150 mesh) were obtained from Sigma-Aldrich and used as received. Chloroform (99.9\% HPLC grade), $N, N$-dimethylformamide (DMF, 99.9\% HPLC grade), dioxane (99\%) and methanol (99\%) were received from Fisher Scientific and used as received. Pentafluorostyrene (PFS, 99\%) was purchased 
from Oakwood Chemicals, and 2-vinyl naphthalene (VN, 97\%) was received from VWR International. $N$-(2-Methylpropyl)- $N$-(1-diethylphosphono-2,2-dimethylpropyl)-O-(2-carboxylprop-2-yl) hydroxylamine (99\%, BlocBuilder ${ }^{\circledR}$ ) and tert-butyl[1-(diethoxyphosphoryl)-2,2-dimethylpropyl]amino nitroxide (SG1, > 85\%) was received from Arkema. 5-methacryloyloxy-2,6-norboranecarbolactone (NLAM) was received from Kuraray and used as received. Styrene (ST, 99\%) and p-acetoxystyrene (AcOST, 99\%) were both received from Sigma-Aldrich and were purified to remove the inhibitor by passing through a column of basic alumina mixed with $5 \mathrm{wt} \%$ calcium hydride and then stored in a sealed flask under a head of nitrogen in a refrigerator until needed. 2,2'-Azoisobutyronitrile (AIBN, 98\%) was received from Sigma-Aldrich and was purified by re-crystallization from methanol. The deuterated chloroform $\left(\mathrm{CDCl}_{3}, 99 \%\right)$ used as a solvent for nuclear magnetic resonance (NMR) was obtained from Cambridge Isotopes Laboratory.

\subsection{Synthesis of NLAM Random Copolymers}

The syntheses were done in a 25-mL three-necked round bottom glass flask equipped with a reflux condenser, a thermal well and a magnetic stir bar. The flask was placed inside a heating mantle and the whole set-up mounted on top of a magnetic stirrer. Table 1 lists the formulations studied for the NLAM/X ( $\mathrm{X}=$ controlling co-monomer) copolymerizations (Scheme 2). For example, for the experiment NLAM-AcOST-5, BlocBuilder (0.0498 g, $0.13 \mathrm{mmol})$, SG1 (0.0036 g, $0.013 \mathrm{mmol}$ ), NLAM (3.15 g, $14.2 \mathrm{mmol}$ ), purified AcOST (0.125 g, $0.77 \mathrm{mmol}$ ) and 1,4 dioxane (6.08 g, $69 \mathrm{mmol})$ were added to the reactor, and then, the reactor was sealed with a rubber septa. The thermocouple connected to a temperature controller was placed inside a thermal well and connected through one of the necks. A mixture of glycol/water (90/10 vol\%) at a temperature of $5^{\circ} \mathrm{C}$ was circulated (NesLab RTE 740 refrigerating circulator) through the condenser connected to one of the necks of the reactor to prevent any evaporation loss of the monomers and/or solvent. A purge of ultra-pure nitrogen was then introduced to the reactor for $30 \mathrm{~min}$ (while maintaining the reactor temperature at $40{ }^{\circ} \mathrm{C}$ to facilitate dissolution) to deoxygenate the reactants prior to polymerization. The purge was vented through the reflux condenser.

After purging at $40{ }^{\circ} \mathrm{C}$ for $30 \mathrm{~min}$, the reactor was heated at a rate of about $10^{\circ} \mathrm{C} \mathrm{min}{ }^{-1}$ to $90{ }^{\circ} \mathrm{C}$ with continuous nitrogen purge. The time at which the reactor temperature reached $90{ }^{\circ} \mathrm{C}$ was taken arbitrarily as the start of the reaction. Samples were then taken from the reactor periodically by a syringe until the samples became too viscous to withdraw. Then, reactions were stopped by removing the reactor from the heating mantle and letting the contents cool down to room temperature, while under continuous nitrogen purge. For each sample withdrawn during the polymerization, the polymer was precipitated twice with excess methanol. After filtration and recovery, the precipitated polymer was dried at $40{ }^{\circ} \mathrm{C}$ under vacuum in the oven overnight to remove any solvent and unreacted monomers. Gel permeation chromatography (GPC) was performed using narrow distribution, linear poly(methyl methacrylate) (PMMA, Agilent Technologies, molecular weight range $875 \mathrm{~g} \mathrm{~mol}^{-1}$ to 1,677,000 $\mathrm{g} \mathrm{mol}^{-1}$ ) as standards with HPLC grade DMF with $0.1 \mathrm{wt} \% \mathrm{LiBr}$ as the eluent at $50{ }^{\circ} \mathrm{C}$, with the exception of NLAM/AcOST, copolymers for which HPLC grade chloroform was used as the eluent. Specifications of the GPC are described more fully in the Characterization section. 
Table 1. Formulations for 5-methacryloyloxy-2,6-norboranecarbolactone (NLAM)/X ( $\mathrm{X}=$ controlling co-monomer) random copolymerizations initiated by BlocBuilder at $90{ }^{\circ} \mathrm{C}$ in $35 \mathrm{wt} \%$ 1,4 dioxane solution.

\begin{tabular}{|c|c|c|c|c|c|c|}
\hline $\begin{array}{c}\text { Sample } \\
\text { ID\# }\end{array}$ & $\begin{array}{c}{\left[\begin{array}{c}\text { [BlocBuilder }]_{0} \\
\left(\mathrm{~mol} \mathrm{~L}^{-1}\right)\end{array}\right.} \\
\end{array}$ & $\begin{array}{l}{[\mathrm{NLAM}]_{0}} \\
\left(\mathrm{~mol} \mathrm{~L}^{-1}\right)\end{array}$ & $\begin{array}{c}{[\mathrm{X}]_{0}} \\
\left(\mathrm{~mol} \mathrm{~L}^{-1}\right)\end{array}$ & $\begin{array}{c}{[\mathrm{SG} 1]_{0}} \\
\left(\mathrm{~mol} \mathrm{~L}^{-1}\right)\end{array}$ & $f_{X, 0}$ & $\begin{array}{c}{[\text { Dioxane }]_{0}} \\
\left(\mathrm{~mol} \mathrm{~L}^{-1}\right)\end{array}$ \\
\hline NLAM/AcOST-5 & 0.024 & 2.4 & 0.10 & 0.0024 & 0.05 & 11.6 \\
\hline NLAM/AcOST-10 & 0.023 & 2.3 & 0.27 & 0.0023 & 0.11 & 11.6 \\
\hline NLAM/ST-5 & 0.022 & 2.4 & 0.13 & 0.0024 & 0.05 & 11.5 \\
\hline NLAM/ST-10 & 0.022 & 2.4 & 0.26 & 0.0020 & 0.10 & 11.6 \\
\hline NLAM/VN-5 & 0.022 & 2.6 & 0.14 & 0.0022 & 0.05 & 11.6 \\
\hline NLAM/VN-10 & 0.025 & 2.5 & 0.33 & 0.0021 & 0.11 & 11.4 \\
\hline NLAM/PFS-5 & 0.024 & 2.4 & 0.13 & 0.0021 & 0.05 & 11.5 \\
\hline NLAM/PFS-10 & 0.020 & 1.6 & 0.17 & 0.0022 & 0.10 & 11.5 \\
\hline
\end{tabular}

$[\mathrm{X}]_{0}$ is the initial concentration of controlling co-monomer in the formulation (X = p-acetoxystyrene (AcOST), styrene (ST), vinylnaphthalene (VN), pentafluorostyrene (PFS)), and $f_{X, 0}$ is the initial molar fraction of the controlling co-monomer.

Scheme 2. The $\mathrm{NLAM} / \mathrm{X}$ copolymerization initiated by BlocBuilder $^{\circledR}$ at $90{ }^{\circ} \mathrm{C}$ in 1,4-dioxane using the various co-monomers: (a) p-acetoxystyrene (AcOST); (b) styrene (ST); (c) 2-vinyl naphthalene (VN); and (d) pentafluorostyrene (PFS).

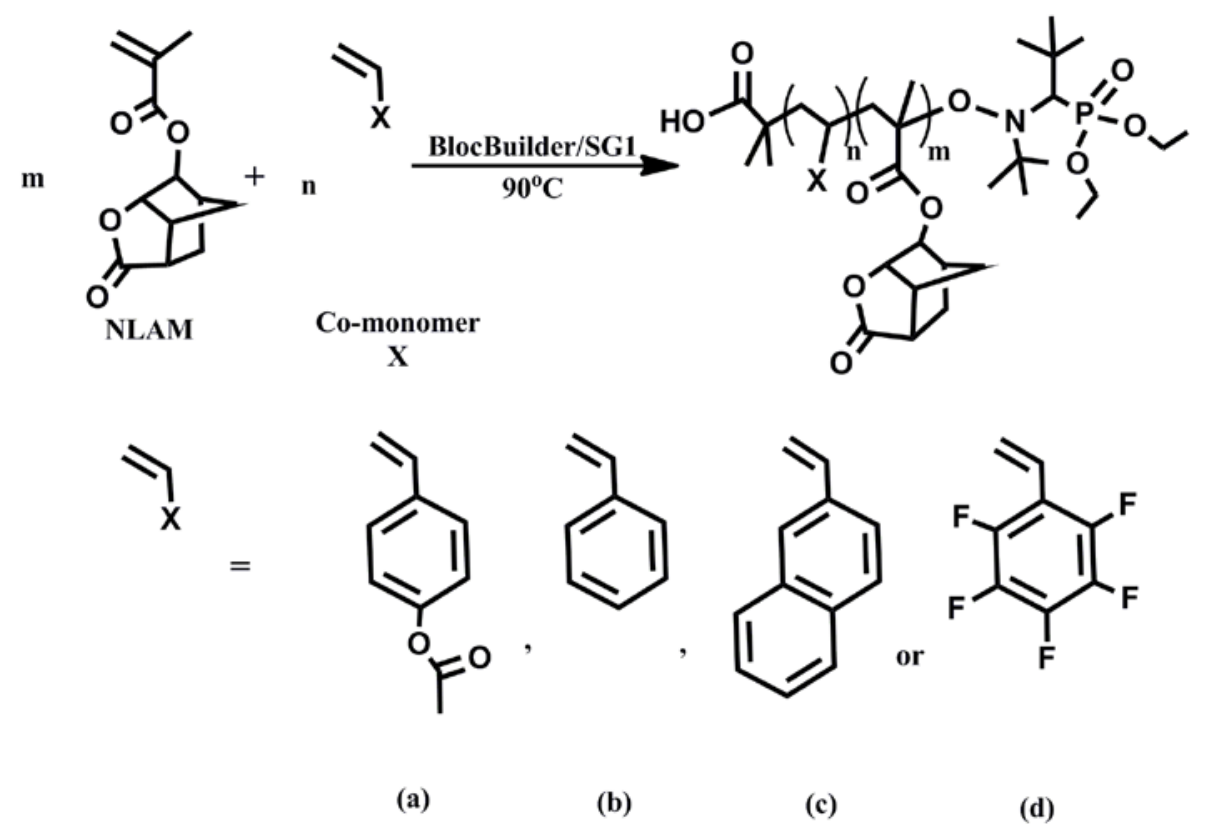

${ }^{1} \mathrm{H}$ NMR (400 MHz, $\mathrm{CDCl}_{3}$, TMS) for poly(NLAM-ran-AcOST): (ppm) 4.3-4.75 (m, 2H, OCHCHO of the norbornene-lactone ring of NLAM, 3.15-3.3 (m, 1H, CHCOO of NLAM), 2.30-2.70 (m, 4H, $2 \times \mathrm{CH}_{2} \mathrm{CHCOO}$ of the norbornene-lactone ring of NLAM), 6.9-7.1 (s, 4 $\mathrm{H}_{\text {aromatic }}$ in AcOST).

${ }^{1} \mathrm{H}$ NMR (400 MHz, $\mathrm{CDCl}_{3}$, TMS) for poly(NLAM-ran-ST): (ppm) 4.3-4.75 (m, 2H, OCHCHO of the norbornene-lactone ring of NLAM, 3.15-3.3 (m, 1H, CHCOO of NLAM), 2.30-2.70 (m, 4H, $2 \times \mathrm{CH}_{2} \mathrm{CHCOO}$ of the norbornene-lactone ring of NLAM), 6.9-7.1 (m, 5 $\mathrm{H}_{\text {aromatic }}$ in ST). 
${ }^{1} \mathrm{H}$ NMR (400 MHz, $\mathrm{CDCl}_{3}$, TMS) for poly(NLAM-ran-VN): (ppm) 4.3-4.75 (m, 2H, OCHCHO of the norbornene-lactone ring of NLAM, 3.15-3.3 (m, 1H, CHCOO of NLAM), 2.30-2.70 (m, 4H, $2 \times \mathrm{CH}_{2} \mathrm{CHCOO}$ of the norbornene-lactone ring of NLAM), 7.25-7.8 (m, $7 \mathrm{H}_{\text {aromatic }}$ in $\mathrm{VN}$ ).

${ }^{13} \mathrm{C}$ NMR (500 MHz, $\left.\mathrm{CDCl}_{3}, \mathrm{TMS}\right)$ for poly(NLAM-ran-PFS): (ppm) 168.5-180 (O-C=O), 136.5-147 (C-F), 114.5-118 (C $\mathrm{C}_{\text {aromatic }}$ in PFS), 76-85.5 (-CH- in norbornene-lactone ring of NLAM), 31.5-46 $\left(-\mathrm{CH}_{2}-\right.$ in NLAM, $-\mathrm{CH}_{2}-$ in PFS), 18.5-21 ( $-\mathrm{CH}_{2}-$ in norbornene-lactone ring of NLAM).

\subsection{Synthesis of Poly(NLAM) by Free Radical Polymerization}

Poly(NLAM) was also synthesized by conventional free radical polymerization using 2,2'-azoisobutyronitrile (AIBN) as the initiator at $80{ }^{\circ} \mathrm{C}$ in 30 wt\% dioxane solution. Zero-point-zero-six-two grams $(0.38 \mathrm{mmol})$ of AIBN, $6.19 \mathrm{~g}(27.9 \mathrm{mmol}) \mathrm{NLAM}$ and $20.5 \mathrm{~g}$ (232 mmol) dioxane were added to a 50 - $\mathrm{mL}$ reactor. The setup and procedures followed were the same as described above. The reaction was stopped after $50 \mathrm{~min}$, and the resulting polymer was precipitated in methanol and dried at $40{ }^{\circ} \mathrm{C}$ under vacuum. The final polymer $\left(\bar{M}_{n}=22,900 \mathrm{~g} \mathrm{~mol}^{-1}, \bar{M}_{w} / \bar{M}_{n}=1.73\right)$ was characterized by GPC relative to poly(methyl methacrylate) (PMMA) standards at $40{ }^{\circ} \mathrm{C}$. This homopolymer was to be used as a comparison against the copolymers for the UV absorption experiments.

\subsection{Chain Extension Experiments}

Statistical copolymers NLAM/PFS-5 and NLAM/VN-10 were chain extended with PFS and VN, respectively, at $110{ }^{\circ} \mathrm{C}$ in $35 \mathrm{wt} \%$ dioxane solution. Copolymers containing PFS or VN are chosen because there has been little study done on their controlling abilities in NMP [60,61]. The experimental setup and procedures were the same as the syntheses for the statistical copolymers, NLAM/X, described earlier. For the chain extension of NLAM/PFS-5 with PFS, $0.60 \mathrm{~g}$ (2.7 mmol) macroinitiator, $1.1 \mathrm{~g}$ (5.6 mmol) PFS and $3.2 \mathrm{~g}$ (36 mmol) 1,4 dioxane were added to the reactor. Similarly, for the chain extension of NLAM/VN-10 with VN, $0.6 \mathrm{~g}$ ( $2.8 \mathrm{mmol})$ macroinitiator, $0.9 \mathrm{~g}$ (5.8 mmol) VN and $2.8 \mathrm{~g}$ (32 mmol) 1,4 dioxane were used. The reactions were stopped after about $3.5 \mathrm{~h}$, and the polymer was then precipitated in methanol and dried in a vacuum oven at $40{ }^{\circ} \mathrm{C}$ overnight. The chain-extended products were characterized by GPC calibrated with poly(methyl methacrylate) standards (see the Characterization section for more details).

\subsection{Characterization}

The overall monomer conversion was determined by ${ }^{1} \mathrm{H}$ nuclear magnetic resonance (NMR) for all the copolymerizations, except the NLAM/PFS systems, for which gravimetry was used, due to the lack of protons in the PFS aromatic ring. The ${ }^{1} \mathrm{H}$ NMR measurements were done with a $400 \mathrm{MHz}$ Varian VNMRS spectrometer using $\mathrm{CDCl}_{3}$ solvent with 16 scans. ${ }^{13} \mathrm{C}$ nuclear magnetic resonance (NMR) was used to estimate the copolymer compositions of NLAM/PFS copolymers. The ${ }^{13} \mathrm{C}$ NMR measurements were done with a $500 \mathrm{MHz}$ Varian VNMRS spectrometer using $\mathrm{CDCl}_{3}$ solvent with 5000 scans. The molecular weight distributions were measured using gel permeation chromatography (GPC, Water Breeze) with HPLC grade chloroform or DMF with $0.1 \mathrm{wt} \% \mathrm{LiBr}$ as the mobile phase. A mobile phase 
flow rate of $0.3 \mathrm{~mL} \mathrm{~min}^{-1}$ was applied, and the GPC was equipped with 3 Waters Styragel ${ }^{\circledR} \mathrm{HR}$ columns (HR1 with a molecular weight measurement range of $10^{2}-10^{3} \mathrm{~g} \mathrm{~mol}^{-1}$, HR2 with a molecular weight measurement range of $5 \times 10^{2}-5 \times 10^{4} \mathrm{~g} \mathrm{~mol}^{-1}$ and HR4 with a molecular weight measurement range $5 \times 10^{3}-6 \times 10^{5} \mathrm{~g} \mathrm{~mol}^{-1}$ ); and, a guard column was used. The columns were heated to $50{ }^{\circ} \mathrm{C}$ during the analysis. The molecular weights were determined by calibration with linear narrow molecular weight distribution poly(methyl methacrylate) (PMMA) standards, and the GPC was equipped with a differential refractive index (RI 2410) detector. The differential scanning calorimetry (DSC) was carried out on a Q2000 (TA instruments, New Castle, DE, USA) at a heating rate of $10{ }^{\circ} \mathrm{C} \mathrm{min}{ }^{-1}$. Calibrations for temperature and heat flow were done using indium and benzoic acid standards, respectively, and the resulting glass transition temperatures $\left(\mathrm{T}_{\mathrm{g}}\right)$ were calculated using the inflection method from the change in slope observed in the DSC traces. Resist polymers were dissolved in cyclopentanone/DMF $(80 / 20 \mathrm{vol} / \mathrm{vol})$ at $20-30 \mathrm{wt} \%$ relative to the solvents and spin coated at $2000 \mathrm{rpm}$ on 1 -inch quartz slides and then baked at $110^{\circ} \mathrm{C}$ for $90 \mathrm{~s}$. After baking, the absorption spectra of the polymers were measured by a Cary 5000 UV-Vis-NIR Spectrophotometer. Film thickness was determined using an Ambios XP-200 profilometer.

\section{Results and Discussion}

\subsection{Kinetics of NLAM/X Random Copolymerizations ( $X=$ Controlling Comonomer)}

The random copolymerizations of NLAM with small amounts of different controlling co-monomer X (X = AcOST, ST, VN or PFS) were done by NMP using BlocBuilder ${ }^{\circledR}$ as the initiator in $35 \mathrm{wt} \%$ 1,4 dioxane solution at $90{ }^{\circ} \mathrm{C}$. The semi-logarithmic kinetic plots of $\ln \left[(1-x)^{-1}\right](x=$ monomer conversion) versus time are illustrated in Figure 1. The slopes of these plots were typically obtained from the linear fit of about five to seven sample points. The slope represents the apparent rate constant, $\left\langle k_{p}\right\rangle$ [P•] (Table 2), where $\left\langle k_{p}\right\rangle$ is the average propagation rate constant and [P•] is the concentration of the propagating macro-radicals. For the systems studied here, the $\left\langle k_{p}\right\rangle[\mathrm{P} \bullet$ reported were all obtained during the early stage of the polymerization, where the number average molecular weight increased linearly with conversion. From these values, $\left\langle k_{p}\right\rangle\langle K\rangle$ can be estimated from Equation (1), where $\left\langle k_{p}\right\rangle$ is the average propagation rate constant for the copolymerization, [P-SG1] is the concentration of the macroalkoxyamine, which is assumed to be equal to [BlocBuilder $]_{0}$, and $r$ is the ratio of the initial concentration of free nitroxide to BlocBuilder: $[\mathrm{SG} 1]_{0} /[\text { BlocBuilder }]_{0}$.

$$
\left\langle k_{p}\right\rangle\langle K\rangle \cong\left\langle k_{p}\right\rangle \frac{[P \cdot][S G 1 \cdot]_{0}}{[\text { BlocBuilder }]_{0}}=\left\langle k_{p}\right\rangle[P \cdot] r
$$

As shown in Figure 1, the kinetic plots are fairly linear with respect to the copolymerization time. Table 2 summarizes the experimental $\left\langle k_{p}\right\rangle\langle K\rangle$ values for the various copolymerizations studied. The apparent rate generally increased with decreasing concentration of controlling co-monomers in the feed, with the exception of the NLAM/ST system. We initially surmised that the excess free nitroxide added was slightly higher for NLAM/ST-5 compared to NLAM/ST-10, which would stabilize the system with the lower concentration of the controlling co-monomer. Even after adjusting for the concentration in the free nitroxide used, the difference in $\left\langle k_{p}\right\rangle\langle K\rangle$ was not significantly different between the two compositions. Thus, only a detailed copolymerization study of the NLAM/ST system over a wider 
composition range could help determine when the apparent rate constant would sharply increase with decreasing ST content. Lessard et al. examined the random copolymerizations of different methacrylates with styrene as the controlling co-monomer under similar condition to ours and reported the $\left\langle k_{p}\right\rangle\langle K\rangle$ value of $(9.8 \pm 0.3) \times 10^{-6} \mathrm{~s}^{-1}$ for the copolymerization of butyl methacrylate with $8.0 \mathrm{~mol} \%$ styrene in the feed [62]. This is comparable to the $\left\langle k_{p}\right\rangle\langle K\rangle$ values obtained in the NLAM/ST system investigated in this study, which were $(1.0 \pm 0.1) \times 10^{-5} \mathrm{~s}^{-1}$ and $(8.4 \pm 0.6) \times 10^{-6} \mathrm{~s}^{-1}$ for $5 \mathrm{~mol} \%$ and $10 \mathrm{~mol} \%$ styrene in the feed, respectively. Furthermore, Miyazaki et al. studied the synthesis of NLAM via ATRP in DMF and o-dichlorobenzene (ODCB) solution with a target $\bar{M}_{n}$ of $22.3 \mathrm{~kg} \mathrm{~mol}^{-1}$ at $70{ }^{\circ} \mathrm{C}$ using $1 \mathrm{M}$ equivalent of EtBrP (ethyl 2-bromopropionate) as the initiator, $1 \mathrm{M}$ equivalent of $\mathrm{CuBr}$ as the catalyst and $4 \mathrm{M}$ equivalent of PMDETA (pentamethyltriethylenetetramine) as the ligand $([\mathrm{M}]:[\mathrm{I}]:[\mathrm{Cu}]:[\mathrm{L}]=100: 1: 1: 4)$ and obtained an apparent rate constant, $\left\langle k_{p}\right\rangle[\mathrm{P} \bullet]$, of $8.2 \times 10^{-5} \mathrm{~s}^{-1}$ [37], which is not too dissimilar to the apparent rate constants observed in this study (i.e., $(1.2 \pm 0.1) \times 10^{-4} \mathrm{~s}^{-1}$ for NLAM/AcOST-5, $(9.2 \pm 0.8) \times 10^{-5} \mathrm{~s}^{-1}$ for NLAM/ST-5, $(7.3 \pm 0.6) \times 10^{-5} \mathrm{~s}^{-1}$ for NLAM/VN-5 and $(5.3 \pm 0.4) \times 10^{-5} \mathrm{~s}^{-1}$ for NLAM/PFS-5). Furthermore, there seem to be insignificant differences in the apparent rate constants for copolymerizations done with the various co-monomers studied, which can be due to the similarities in the chemical structure of the co-monomer and the low co-monomer initial feed concentration used.

Figure 1. The kinetic plots of $\ln \left[(1-x)^{-1}\right](x=$ conversion $)$ versus polymerization time for NLAM/X (X = p-acetoxystyrene (AcOST), styrene (ST), 2-vinyl naphthalene (VN) or pentafluorostyrene (PFS)) random copolymerization initiated by BlocBuilder ${ }^{\circledR}$ in 1,4 dioxane solution at $90{ }^{\circ} \mathrm{C}$ : (a) NLAM/AcOST-5 (口), NLAM/AcOST-10 (घ);

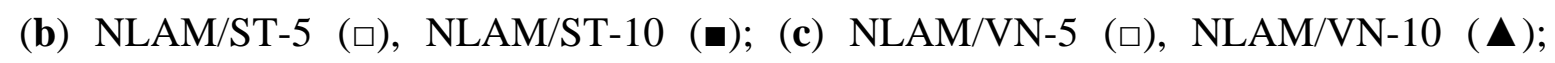
(d) NLAM/PFS-5 (口), NLAM/PFS-10 ( $\mathbf{\Delta})$. The straight solid lines are the best linear fit of the experimental data points.
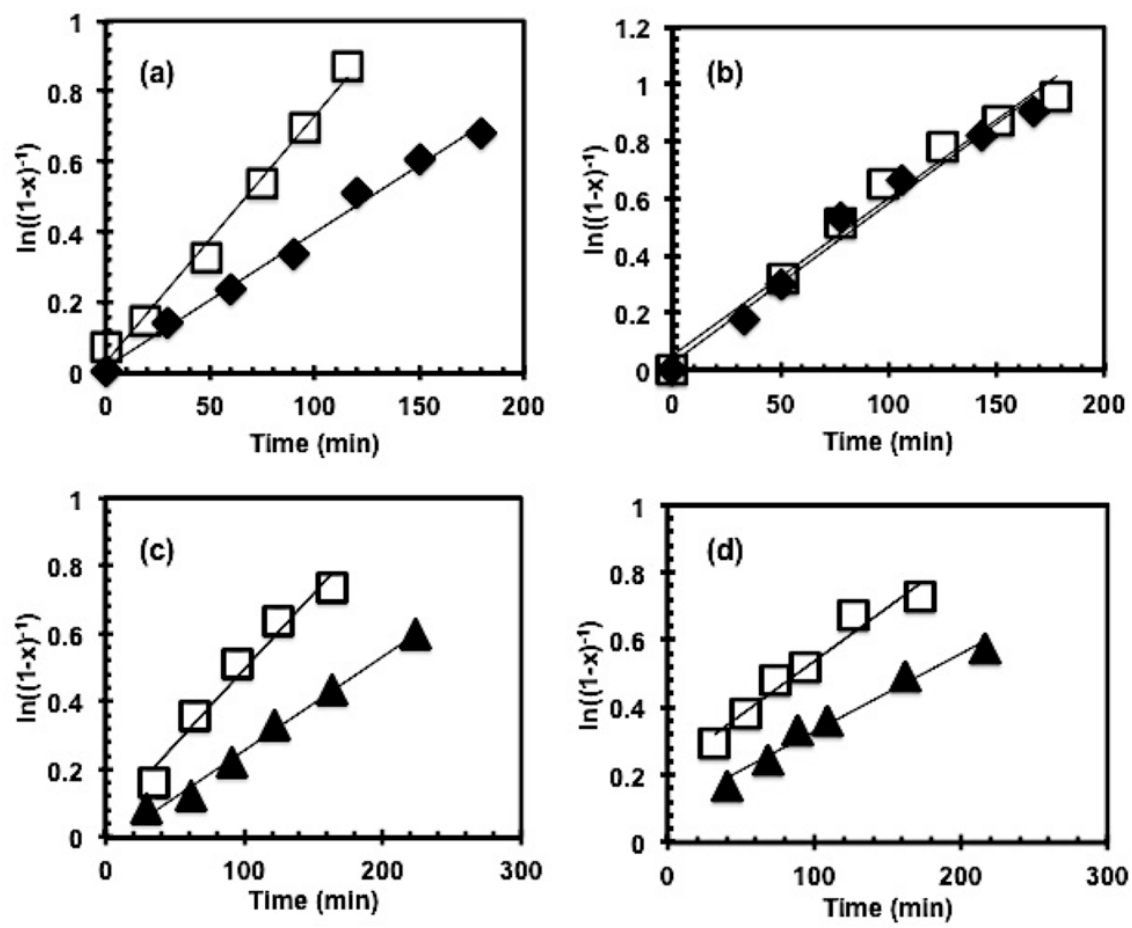
Table 2. The summary of copolymerization kinetic data of 5-methacryloyloxy-2,6-norboranecarbolactone (NLAM)/X (X = controlling co-monomer) controlled by BlocBuilder ${ }^{\circledR}$ at $90^{\circ} \mathrm{C}$ in $35 \mathrm{wt} \%$ 1,4 dioxane solution.

\begin{tabular}{ccccc}
\hline Experimental ID & $\boldsymbol{f}_{\boldsymbol{X}, \mathbf{0}}$ & $\boldsymbol{r}$ & $\left.\left\langle\boldsymbol{k}_{\boldsymbol{p}}\right\rangle\langle\boldsymbol{K}\rangle \mathbf{s}^{\mathbf{- 1}}\right)$ & $\left.\left\langle\boldsymbol{k}_{\boldsymbol{p}}\right\rangle[\boldsymbol{P} \cdot] \mathbf{s}^{-\mathbf{1}}\right)$ \\
\hline NLAM/AcOST-5 & 0.05 & 0.10 & $(1.2 \pm 0.1) \times 10^{-5}$ & $(1.2 \pm 0.1) \times 10^{-4}$ \\
NLAM/AcOST-10 & 0.11 & 0.10 & $(6.3 \pm 0.5) \times 10^{-6}$ & $(6.3 \pm 0.5) \times 10^{-5}$ \\
NLAM/ST-5 & 0.05 & 0.11 & $(1.0 \pm 0.1) \times 10^{-5}$ & $(9.2 \pm 0.8) \times 10^{-5}$ \\
NLAM/ST-10 & 0.10 & 0.09 & $(8.4 \pm 0.6) \times 10^{-6}$ & $(9.3 \pm 0.7) \times 10^{-5}$ \\
NLAM/VN-5 & 0.05 & 0.10 & $(7.3 \pm 0.6) \times 10^{-6}$ & $(7.3 \pm 0.6) \times 10^{-5}$ \\
NLAM/VN-10 & 0.11 & 0.08 & $(3.8 \pm 0.4) \times 10^{-6}$ & $(4.7 \pm 0.5) \times 10^{-5}$ \\
NLAM/PFS-5 & 0.05 & 0.09 & $(4.8 \pm 0.4) \times 10^{-6}$ & $(5.3 \pm 0.4) \times 10^{-5}$ \\
NLAM/PFS-10 & 0.10 & 0.10 & $(3.8 \pm 0.3) \times 10^{-6}$ & $(3.8 \pm 0.4) \times 10^{-5}$ \\
\hline
\end{tabular}

$f_{X, 0}$ is the initial molar fraction of the controlling co-monomer in the formulation ( $\mathrm{X}=\mathrm{p}$-acetoxystyrene (AcOST), styrene (ST), vinylnaphthalene (VN), pentafluorostyrene (PFS)).

\subsection{Characterization of NLAM/X Statistical Copolymers}

The evolution of the number average molecular weight $\left(\bar{M}_{n}\right)$ versus conversion is plotted in Figure 2. A linear increase of $\bar{M}_{n}$ with conversion is one of the key features of a living polymerization. All the NLAM/X copolymerizations, although not true living systems, exhibited superficially living characteristics and showed a linear trend of $\bar{M}_{n}$ versus conversion up to about 50\% conversion, except the NLAM/ST system, which remained fairly linear up to $60 \mathrm{~mol} \%$ conversion. At higher conversions, the plots tend to plateau. The reason for the plateau could be attributed to the chain transfer side reactions to the solvent and monomers, which become more prevalent at higher conversions [63]. However, it should be noted that the styrenic comonomer tended to be incorporated preferentially into each of the copolymers, and the preferential incorporation could have led to irreversible termination reactions at a higher conversion, as the controlling co-monomer concentration would be steadily depleted or removed completely. The polymerization control could be lost in such cases. This would result in lower apparent average molecular weight and higher dispersities $\left(\bar{M}_{w} / \bar{M}_{n}\right)$, since new chains were created when the radicals transfer to monomer or solvent molecules. The newly created chains are probably still able to polymerize in a controlled manner, but with a significant fraction of new chains at low molecular weight, this would result in a lower than expected $\bar{M}_{n}$ and a broader molecular weight distribution. Greszta et al. demonstrated that the combination of chain transfer to monomer and alkoxyamine decomposition were the main reasons for lower $\bar{M}_{n}$ and higher $\bar{M}_{w} / \bar{M}_{n}$ at high conversions in the polymerization of styrene with TEMPO nitroxide [63].

All GPC characterizations of NLAM/X copolymers were initially done using chloroform as the eluent. However, it was observed that except for the NLAM/AcOST copolymers, the other copolymers showed undesired absorption issues with the columns, such as abnormally long low-molecular weight tailing. Consequently, the molecular weights for the NLAM/ST, NLAM/VN and NLAM/PFS copolymers were measured again using DMF with $0.1 \mathrm{wt} \%$ of $\mathrm{LiBr}$ as the eluent. It should be noted that the experimentally measured $\bar{M}_{n}$ s (Figure 2b-d) are slightly above the theoretical lines. This could be ascribed to the polymer-column, polymer-solvent interactions induced by the addition of $\mathrm{LiBr}$ in the DMF eluent, which was used to avoid the adsorption problems observed in the GPC 
chromatograms $[64,65]$. As a side effect, the retention volumes of GPC measurements could be higher or lower than those in pure DMF, depending on the polymers and columns used [64-67]. In this case, the Styragel columns, being negatively charged, repel the weakly negatively charged polymer coils and, thus, resulted in a slightly lower retention time or higher apparent molecular weight than would be expected [67]. Furthermore, it should be noted that the GPC measurements were based on calibration by PMMA, which may lead to a discrepancy, due to its structural difference from NLAM copolymers.

Figure 2. The number average molecular weight $\left(\bar{M}_{n}\right)$, determined by gel permeation chromatography (GPC) relative to poly(methyl methacrylate) standards in chloroform (a) or N,N-dimethylformamide (DMF) (b, c and d) and dispersity $\left(\bar{M}_{w} / \bar{M}_{n}\right)$ versus conversion for various NLAM/X (X = controlling co-monomer) random copolymerization initiated by BlocBuilder $^{\circledR}$ in 1,4 dioxane solution at $90 \bar{M}_{w} / \bar{M}_{n} \mathrm{C}$ : (a) NLAM/AcOST-5 (口),

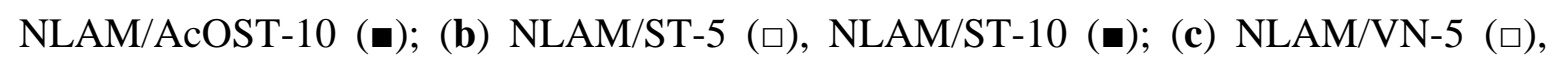
NLAM/VN-10 ( $\boldsymbol{\Delta}$ ); (d) NLAM/PFS-5 ( $\square$ ), NLAM/PFS-10 ( $\boldsymbol{\Delta}$ ). The straight solid indicates the theoretical $\bar{M}_{n}$ versus conversion based on the monomer to initiator ratio for the particular experiment. All characterization of experiments is listed in Table 3.
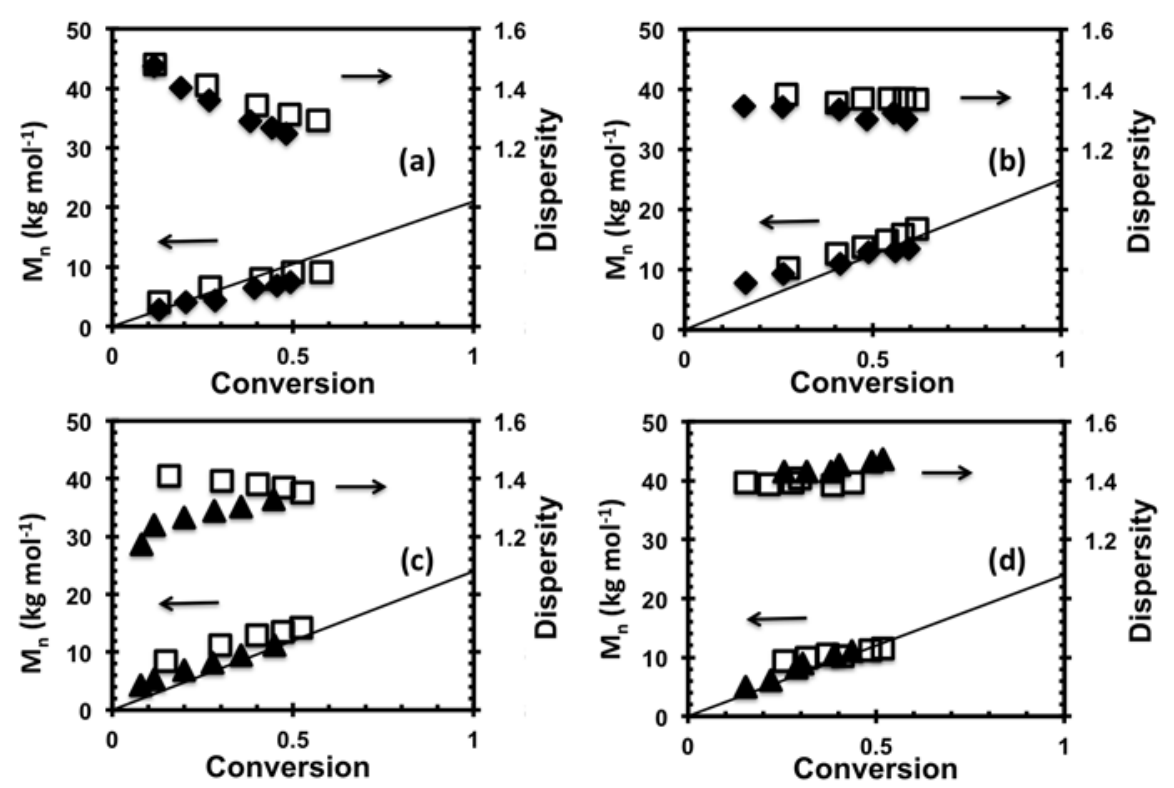

The characterization of all copolymers synthesized is summarized in Table 3. All the final copolymers are fairly NLAM-rich and had $\bar{M}_{w} / \bar{M}_{n}$ s of around 1.3, except that of the NLAM/PFS-5 copolymer, which had $\bar{M}_{w} / \bar{M}_{n}$ of 1.47 . P-acetoxystyrene (AcOST), which has been employed in the past as a key component in 248-nm photoresists [68], exhibited the best controlling ability based on the lowest dispersity $\left(\bar{M}_{w} / \bar{M}_{n} \sim 1.29\right)$ at a concentration as low as 5 mol\% in the feed. Pentafluorostyrene (PFS), also offering relatively good control $\left(\bar{M}_{w} / \bar{M}_{n} \sim 1.47\right.$ and 1.31 for 5 and $10 \mathrm{~mol} \%$ in the feed, respectively), is of interest, because fluorinated polymers have been shown to be good candidates for both 157-nm and 193-nm photoresists, due to their low absorption, good etch resistance properties [69-73] and high hydrophobicity [74,75], which is especially important in immersion lithography. 2-vinyl naphthalene (VN) was also an effective co-monomer in being able to produce copolymers with low dispersities $\left(\bar{M}_{w} / \bar{M}_{n} \sim 1.3\right)$ with as low as $5 \mathrm{~mol} \%$ in the feed. The naphthalene unit 
also showed relatively low absorption at $193 \mathrm{~nm}$ (Figure 3), and its derivatives have been used as chain transfer agents in the syntheses of well-defined 193-nm photoresists by RAFT [40,45]. The absorption spectra (at wavelengths from 185-350 nm) of NLAM-rich copolymers synthesized by NMP and poly(NLAM) $\left(=22,900 \mathrm{~g} \mathrm{~mol}^{-1}, \bar{M}_{w} / \bar{M}_{n}=1.73\right)$ made by conventional free radical polymerization are presented in Figure 3. All polymers exhibited absorbances below $0.8 \mu \mathrm{m}^{-1}$. NLAM/PFS-5 showed a very low absorbance of around $0.2 \mu^{-1}$ at $193 \mathrm{~nm}$, while NLAM-VN-5 and NLAM-ST-5 had relatively higher absorbances of about $0.5-1.0 \mu^{-1}$ at $193 \mathrm{~nm}$, and this could be partially due to the higher mole fractions of VN and ST present in the respective final copolymers. Overall, the small amount of the controlling co-monomers added did not significantly affect the optical transparency of the poly(NLAM)-rich copolymers at $193 \mathrm{~nm}$ compared to pure poly(NLAM), and all the copolymers exhibited absorbance levels comparable to other 193-nm candidate photoresist materials previously reported in the literature [76-79].

Table 3. Molecular characterization of NLAM/X (X = controlling co-monomer) random copolymers synthesized at $90{ }^{\circ} \mathrm{C}$ in 35 wt\% 1,4 dioxane solution with BlocBuilder ${ }^{\circledR}$ and additional SG1 free nitroxide.

\begin{tabular}{cccccccc}
\hline $\begin{array}{c}\text { Sample } \\
\text { ID\# }\end{array}$ & $\mathbf{f}_{\text {comonomer, }}$ & $\begin{array}{c}\text { Conversion } \\
\boldsymbol{x}\end{array}$ & $\mathbf{F}_{\text {NLAM }}{ }^{\mathbf{a}}$ & $\begin{array}{c}\bar{M}_{n} \\
\mathbf{( g ~ m o l}^{\mathbf{1}} \mathbf{)}\end{array}$ & $\bar{M}_{w} / \bar{M}_{n}$ & $\begin{array}{c}\mathbf{t}_{\text {polymerization }} \\
(\mathbf{m i n})\end{array}$ & $\begin{array}{c}\mathbf{T}_{\mathbf{g}} \\
\left({ }^{\circ} \mathbf{C}\right)\end{array}$ \\
\hline NLAM/AcOST-5 & 0.05 & 0.58 & 0.93 & 9270 & 1.29 & 120 & 108 \\
NLAM/AcOST-10 & 0.11 & 0.49 & 0.85 & 7600 & 1.25 & 180 & 105 \\
NLAM/ST-5 & 0.05 & 0.62 & 0.88 & 16,700 & 1.35 & 180 & 112 \\
NLAM/ST-10 & 0.10 & 0.60 & 0.80 & 13,700 & 1.29 & 170 & 108 \\
NLAM/VN-5 & 0.05 & 0.52 & 0.89 & 13,900 & 1.35 & 165 & 115 \\
NLAM/VN-10 & 0.11 & 0.45 & 0.83 & 11,600 & 1.33 & 220 & 109 \\
NLAM/PFS-5 & 0.05 & 0.52 & 0.91 & 11,400 & 1.47 & 170 & 110 \\
NLAM/PFS-10 & 0.10 & 0.44 & 0.85 & 11,000 & 1.31 & 220 & 107 \\
\hline
\end{tabular}

${ }^{\mathrm{a}} \mathrm{F}_{\mathrm{NLAM}}$ is the molar fraction of NLAM in the final copolymer as determined by ${ }^{13} \mathrm{C}$ NMR for NLAM-PFS copolymers or ${ }^{1} \mathrm{H}$ NMR for the other copolymers.

Figure 3. Absorption spectra of NLAM/X (X = controlling co-monomer) copolymers by nitroxide-mediated polymerization (NMP) and poly(NLAM) by conventional free radical polymerization at wavelengths from $185 \mathrm{~nm}$ to $350 \mathrm{~nm}$.

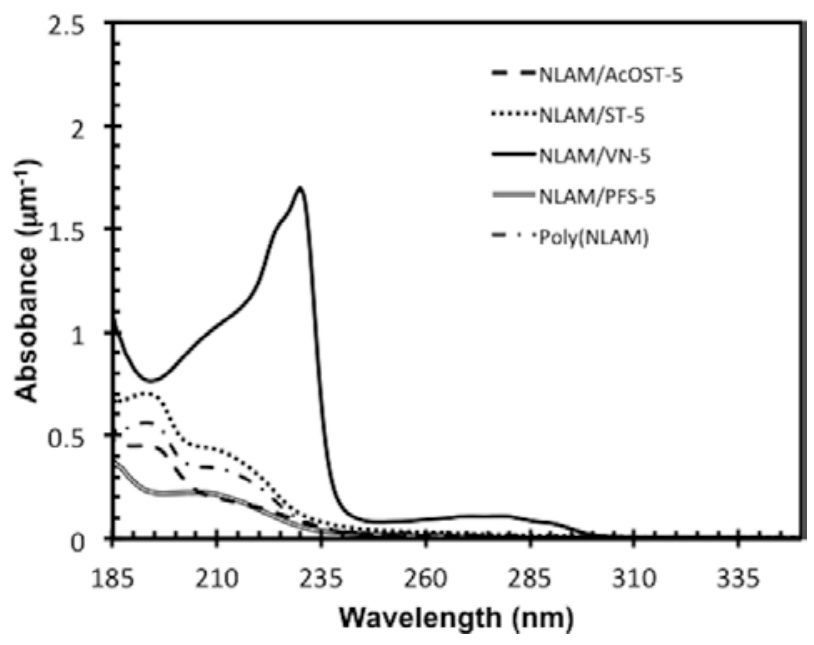




\subsection{Chain Extensions of Selected Copolymers}

The statistical copolymers, NLAM/PFS-5 and NLAM/VN-10, were chain extended by VN and PFS, respectively, to examine their reinitiation ability. Copolymers controlled by PFS and VN were chosen, because PFS showed very low absorbance and VN has never been tested as a controlling co-monomer in NMP [60,61]. The GPC chromatograms of the chain extension are shown in Figure 4. The chain-extended block copolymers (shown as dotted lines) all shifted to lower elution times compared to their macroinitiators (shown as solid lines). The $\bar{M}_{n} \mathrm{~s}$ of the block copolymers were slightly higher compared to those of their respective macroinitators. Indeed, the chain-extended block copolymer, NLAM-PFS-5-PFS, resulted in $\bar{M}_{w} / \bar{M}_{n}$ of 1.56 , while NLAM-VN-10-VN showed $\bar{M}_{w} / \bar{M}_{n}$ of 1.48 (Table 4). These results confirmed the ability of the macroinitiators to reinitiate a new batch of monomer and polymerize in a controlled way, which superficially resembles the features expected of truly living polymers.

Table 4. Molecular characterizations for NLAM/PFS-5 and NLAM/VN-10 chain extensions with PFS and VN, respectively.

\begin{tabular}{ccccccc}
\hline \multirow{2}{*}{ Sample ID } & \multicolumn{3}{c}{ Macroinitiator } & \multicolumn{3}{c}{ Chain-Extended Polymer } \\
\cline { 2 - 6 } & $\bar{M}_{n} \mathbf{( \mathbf { g ~ m o l }} \mathbf{~}^{-\mathbf{1}} \mathbf{)}$ & $\bar{M}_{w} / \bar{M}_{n}$ & $\mathbf{F}_{\mathrm{NLAM}}{ }^{\mathbf{a}}$ & $\bar{M}_{n} \mathbf{( \mathbf { g ~ m o l }}{ }^{-\mathbf{1}} \mathbf{)}$ & $\bar{M}_{w} / \bar{M}_{n}$ & $\mathbf{F}_{\mathrm{NLAM}}{ }^{\mathbf{b}}$ \\
\hline NLAM/PFS-5-PFS & 11,400 & 1.47 & 0.91 & 17,900 & 1.56 & 0.52 \\
NLAM/VN-10-VN & 11,600 & 1.33 & 0.83 & 16,800 & 1.48 & 0.58 \\
\hline${ }^{\mathrm{a}} \mathrm{F}_{\mathrm{NLAM}}$ is the molar fraction of NLAM in the macroinitiator as determined by ${ }^{13} \mathrm{C}$ NMR or ${ }^{1} \mathrm{H}$ NMR; ${ }^{\mathrm{b}} \mathrm{F}_{\mathrm{NLAM}}$ is \\
the molar fraction of NLAM in the final chain-extended polymer as determined by ${ }^{13} \mathrm{C}$ NMR or ${ }^{1} \mathrm{H}$ NMR.
\end{tabular}

Figure 4. GPC chromatograms of macroinitiators (solid line) and chain extended polymers (dotted line) in the chain extension experiments: (a) NLAM/PFS-5-PFS and (b) NLAM/VN-10-VN.
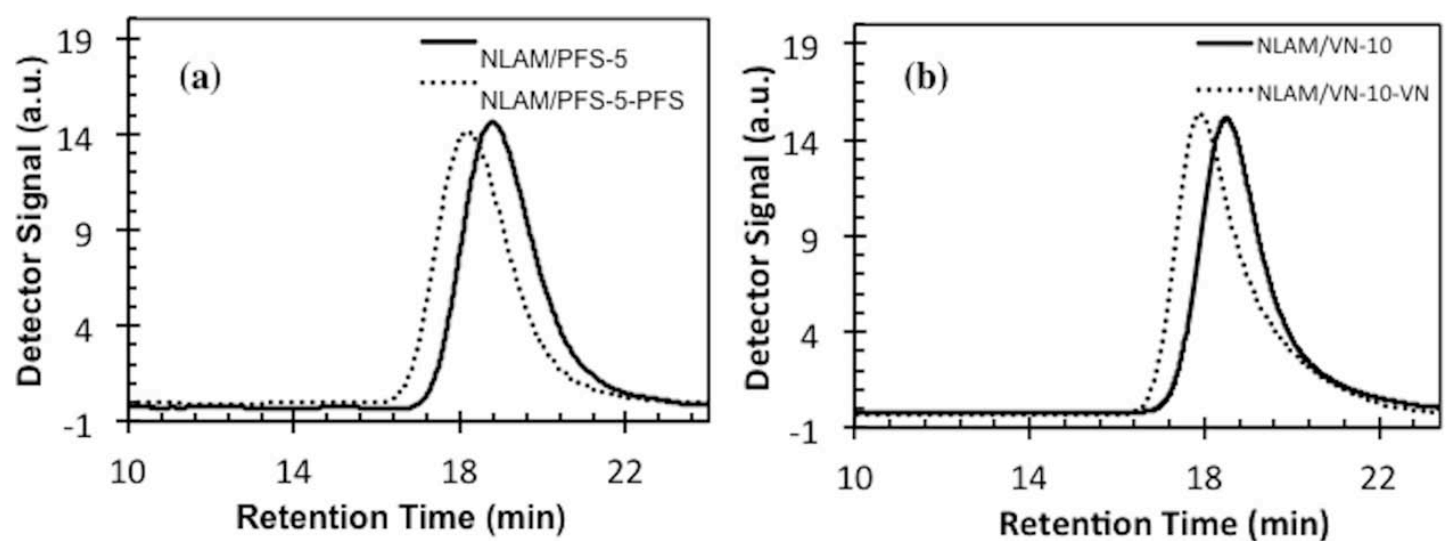

\section{Conclusions}

Well-defined random candidate copolymers rich in NLAM for $193 \mathrm{~nm}$ photoresists were synthesized for the first time by NMP at $90{ }^{\circ} \mathrm{C}$ in 1,4 dioxane solution with BlocBuilder ${ }^{\circledR}$ as the unimolecular initiator. The polymerization kinetics were examined for four different types of controlling co-monomers for NLAM (i.e., AcOST, ST, VN and PFS). In all cases, as little as 5 mol\% controlling co-monomer in the feed was demonstrated to be sufficient in producing the linear evolution of the 
number average molecular weight against conversion in the range studied (up to $50 \%$ conversion), suggesting that the polymerizations were relatively well controlled. Further, the resulting copolymers were characterized by GPC and showed relatively narrow molecular weight distributions ( 1.3 in most cases) and relatively low absorbance, which ensured high optical transparency. Selected copolymers NLAM/PFS-5 and NLAM/VN-10 were used as macroinitiators and successfully chain-extended with new batches of PFS and VN monomers, respectively, at $110^{\circ} \mathrm{C}$ in $35 \mathrm{wt} \%$ dioxane solution.

\section{Acknowledgments}

This work was supported by NanoQuébec College Technology Transfer Center (CCTT) grant, and Z.-J.W. was partially supported by the Eugenie Lamothe Scholarship. The authors thank Motonari Nakamura and Hideki Matsuda of Kuraray Co. Ltd. (Tokyo, Japan) for the kind donation of NLAM, and Scott Schmidt and Noah Mary of Arkema, Inc. (King of Prussia, PA, USA), for their help in obtaining the BlocBuilder ${ }^{\circledR}$ alkoxyamine initiator used in this work.

\section{Conflicts of Interest}

The authors declare no conflict of interest.

\section{References}

1. Hawker, C.J.; Bosman, A.W.; Harth, E. New polymer synthesis by nitroxide mediated living radical polymerizations. Chem. Rev. 2001, 101, 3661-3688.

2. Nicolas, J.; Guillaneuf, Y.; Lefay, C.; Bertin, D.; Gigmes, D.; Charleux, B. Nitroxide-mediated polymerization. Prog. Polym. Sci. 2013, 38, 63-235.

3. Veregin, R.P.N.; Georges, M.K.; Kazmaier, P.M.; Hamer, G.K. Free-radical polymerizations for narrow polydispersity resins: Electron-spin-resonance studies of the kinetics and mechanism. Macromolecules 1993, 26, 5316-5320.

4. Fukuda, T.; Terauchi, T.; Goto, A.; Ohno, K.; Tsujii, Y.; Miyamoto, T.; Kobatake, S.; Yamada, B. Mechanisms and kinetics of nitroxide-controlled free radical polymerization. Macromolecules 1996, 29, 6393-6398.

5. Nicolas, J.; Charleux, B.; Guerret, O.; Magnet, S. Novel SG1-Based water-soluble alkoxyamine for nitroxide-mediated controlled free-radical polymerization of styrene and n-butyl acrylate in miniemulsion. Macromolecules 2004, 37, 4453-4463.

6. Lefay, C.; Charleux, B.; Save, M.; Chassenieux, C.; Guerret, O.; Magnet, S. Amphiphilic gradient poly(styrene-co-acrylic acid) copolymer prepared via nitroxide-mediated solution polymerization. Synthesis, characterization in aqueous solution and evaluation as emulsion polymerization stabilizer. Polymer 2006, 47, 1935-1945.

7. Couvreur, L.; Charleux, B.; Guerret, O.; Magnet, S. Direct synthesis of controlled poly(styrene-co-acrylic acid)s of various compositions by nitroxide-mediated random copolymerization. Macromol. Chem. Phys. 2003, 204, 2055-2063. 
8. Gibbons, O.; Carroll, W.M.; Aldabbagh, F.; Yamada, B. Nitroxide-mediated controlled statistical copolymerizations of N-isopropylacrylamide with N-tert-butylacrylamide. J. Polym. Sci. Polym. Chem. 2006, 44, 6410-6418.

9. Benoit, D.; Chaplinski, V.; Braslau, R.; Hawker, C.J. Development of a universal alkoxyamine for “living” free radical polymerizations. J. Am. Chem. Soc. 1999, 121, 3904-3920.

10. Schierholz, K.; Givehchi, M.; Fabre, P.; Nallet, F.; Papon, E.; Guerret, O.; Gnanou, Y. Acrylamide-based amphiphilic block copolymers via nitroxide-mediated radical polymerization. Macromolecules 2003, 36, 5995-5999.

11. Nicolas, J.; Dire, C.; Mueller, L.; Belleney, J.; Charleux, B.; Marque, S.R.A.; Bertin, D.; Magnet, S.; Couvreur, L. Living character of polymer chains prepared via nitroxide-mediated controlled free-radical polymerization of methyl methacrylate in the presence of a small amount of styrene at low temperature. Macromolecules 2006, 39, 8274-8282.

12. Nicolas, J.; Mueller, L.; Dire, C.; Matyjaszewski, K.; Charleux, B. Comprehensive modeling study of nitroxide-mediated controlled/living radical copolymerization of methyl methacrylate with a small amount of styrene. Macromolecules 2009, 42, 4470-4478.

13. Charleux, B.; Nicolas, J.; Guerret, O. Theoretical expression of the average activation-deactivation equilibrium constant in controlled/living free-radical copolymerization operating via reversible termination. Application to a strongly improved control in nitroxide-mediated polymerization of methyl methacrylate. Macromolecules 2005, 38, 5485-5492.

14. Moayeri, A.; Lessard, B.; Maric, M. Nitroxide mediated controlled synthesis of glycidyl methacrylate-rich copolymers enabled by SG1-based alkoxyamines bearing succinimidyl ester groups. Polym. Chem. 2011, 2, 2084-2092.

15. Zhang, C.; Lessard, B.; Maric, M. Synthesis and characterization of benzyl methacrylate/styrene random copolymers prepared by NMP. Macromol. React. Eng. 2010, 4, 415-423.

16. Lessard, B.H.; Ling, E.J.Y.; Maric, M. Fluorescent, thermoresponsive oligo(ethylene glycol) methacrylate/9-(4-vinylbenzyl)-9H-carbazole copolymers designed with multiple LCSTs via nitroxide mediated controlled radical polymerization. Macromolecules 2012, 45, 1879-1891.

17. Brusseau, S.; Belleney, J.; Magnet, S.; Couvreur, L.; Charleux, B. Nitroxide-mediated copolymerization of methacrylic acid with sodium 4-styrene sulfonate: Towards new water-soluble macroalkoxyamines for the synthesis of amphiphilic block copolymers and nanoparticles. Polym. Chem. 2010, 1, 720-729.

18. Zhang, C.; Maric, M. $\mathrm{pH}-$ and temperature-sensitive statistical copolymers poly[2-(dimethylamino)ethyl methacrylate-stat-2-vinylpyridine] with Functional succinimidyl-ester chain ends synthesized by nitroxide-mediated polymerization. J. Polym. Sci. Polym. Chem. 2012, 50, 4341-4357.

19. Georges, M.K.; Veregin, R.P.N.; Kazmaier, P.M.; Hamer, G.K. Narrow molecular-weight resins by a free-radical polymerization process. Macromolecules 1993, 26, 2987-2988.

20. Nicolas, J.; Ruzette, A.V.; Farcet, C.; Gerard, P.; Magnet, S.; Charleux, B. Nanostructured latex particles synthesized by nitroxide-mediated controlled/living free-radical polymerization in emulsion. Polymer 2007, 48, 7029-7040.

21. Cunningham, M.F.; Lin, M.; Keoshkerian, B. Optimizing nitroxide-mediated miniemulsion polymerization processes. JCT Res. 2004, 1, 33-39. 
22. Charleux, B.; Nicolas, J. Water-soluble SG1-based alkoxyamines: A breakthrough in controlled/living free-radical polymerization in aqueous dispersed media. Polymer 2007, 48, 5813-5833.

23. Ryan, J.; Aldabbagh, F.; Zetterlund, P.B.; Yamada, B. First nitroxide-mediated controlled/living free radical polymerization in an ionic liquid. Macromol. Rapid Commun. 2004, 25, 930-934.

24. Zhang, H.W.; Hong, K.; Mays, J.W. First report of nitroxide mediated polymerization in an ionic liquid. Polym. Bull. 2004, 52, 9-16.

25. Frechet, J.M.J.; Henmi, M.; Gitsov, I.; Aoshima, S.; Leduc, M.R.; Grubbs, R.B. Self-condensing vinyl polymerization: An approach to dendritic materials. Science 1995, 269, 1080-1083.

26. Hawker, C.J.; Frechet, J.M.J.; Grubbs, R.B.; Dao, J. Preparation of hyperbranched and star polymers by a living, self-condensing free-radical polymerization. J. Am. Chem. Soc. 1995, 117, 10763-10764.

27. Miura, Y.; Dote, H. Syntheses of 12-arm star polymers and star diblock copolymers by nitroxide-mediated radical polymerization using dendritic dodecafunctional macroinitiators. J. Polym. Sci. Polym. Chem. 2005, 43, 3689-3700.

28. Kakuchi, T.; Narumi, A.; Matsuda, T.; Miura, Y.; Sugimoto, N.; Satoh, T.; Kaga, H. Glycoconjugated polymer. 5. Synthesis and characterization of a seven-arm star polystyrene with beta-cyclodextrin core based on TEMPO-mediated living radical polymerization. Macromolecules 2003, 36, 3914-3920.

29. Pasquale, A.J.; Long, T.E. Synthesis of star-shaped polystyrenes via nitroxide-mediated stable free-radical polymerization. J. Polym. Sci. Polym. Chem. 2001, 39, 216-223.

30. Narumi, A.; Matsuda, T.; Kaga, H.; Satoh, T.; Kakuchi, T. Synthesis of amphiphilic triblock copolymer of polystyrene and poly(4-vinylbenzyl glucoside) via TEMPO-mediated living radical polymerization. Polymer 2002, 43, 4835-4840.

31. Narumi, A.; Otsuka, I.; Matsuda, T.; Miura, Y.; Satoh, T.; Kaneko, N.; Kaga, H.; Kakuchi, T. Glycoconjugated polymer: Synthesis and characterization of poly(vinyl saccharide)-blockpolystyrene-block-poly(vinyl saccharide) as an amphiphilic ABA triblock copolymer. J. Polym. Sci. Polym. Chem. 2006, 44, 3978-3985.

32. Mohajery, S.; Rahmani, S.; Entezami, A.A. Synthesis of functional polyethylene graft copolymers by nitroxide-mediated living radical polymerization. Polym. Adv. Technol. 2008, 19, 1528-1535.

33. Yoshida, E. Graft copolymerization of methyl methacrylate on polystyrene backbone through nitroxide-mediated photo-living radical polymerization. Colloid Polym. Sci. 2011, 289, 837-841.

34. Appelt, M.; Schmidt-Naake, G. Nitroxide-controlled grafting by an insertion mechanism using a polymerizable N-oxyl. Macromol. Mater. Eng. 2004, 289, 245-253.

35. Yoshida, E. Controlled photoradical polymerization mediated by 2,2,6,6-tetramethylpiperidine1-oxyl. Polymers 2012, 4, 1125-1156.

36. Fleischmann, S.; Percec, V. Synthesis of well-defined photoresist materials by SET-LRP. J. Polym. Sci. Polym. Chem. 2010, 48, 2251-2255.

37. Miyazaki, T.; Xue, B.; Kohno, K.; Hasegawa, E.; Iwasa, S.; Toyota, A. Synthesis of well-defined norbornene-lactone-functionalized polymers via ATRP. Polym. Bull. 2010, 64, 867-875. 
38. Wieberger, F.; Forman, D.C.; Neuber, C.; Groschel, A.H.; Bohm, M.; Muller, A.H.E.; Schmidt, H.W.; Ober, C.K. Tailored star-shaped statistical teroligomers via ATRP for lithographic applications. J. Mater. Chem. 2012, 22, 73-79.

39. Wieberger, F.; Neuber, C.; Ober, C.K.; Schmidt, H.W. Tailored star block copolymer architecture for high performance chemically amplified resists. Adv. Mater. 2012, 24, 5939-5944.

40. Sohn, H.S.; Cha, S.H.; Lee, W.K.; Kim, D.G.; Yun, H.J.; Kim, M.S.; Kim, B.D.; Kim, Y.H.; Lee, J.W.; Kim, J.S.; et al. Synthesis of ArF photoresist polymer composed of three methacrylate monomers via reversible addition-fragmentation chain transfer (RAFT) polymerization. Macromol. Res. 2011, 19, 722-728.

41. Lou, Q.; Kishpaugh, M.A.; Shipp, D.A. Synthesis of statistical and block copolymers containing adamantyl and norbornyl moieties by reversible addition-fragmentation chain transfer polymerization. J. Polym. Sci. Polym. Chem. 2010, 48, 943-951.

42. Sohn, H.S.; Kim, D.G.; Lee, A.; Lee, J.W.; Kim, J.S.; Kim, J.H.; Lee, J.C. Preparation of acid-cleavable branched polymers for argon fluoride photoresists via reversible addition-fragmentation chain-transfer polymerization. J. Appl. Polym. Sci. 2012, 125, 344-352.

43. Ridaoui, H.; Dirani, A.; Soppera, O.; Ismailova, E.; Brochon, C.; Schlatter, G.; Hadziioannou, G.; Tiron, R.; Bandelier, P.; Sourd, C. Chemically amplified photoresists for 193-Nm photolithography: Effect of molecular structure and photonic parameters on photopatterning. J. Polym. Sci. Polym. Chem. 2010, 48, 1271-1277.

44. Chochos, C.L.; Ismailova, E.; Brochon, C.; Leclerc, N.; Tiron, R.; Sourd, C.; Bandelier, P.; Foucher, J.; Ridaoui, H.; Dirani, A.; et al. Hyperbranched polymers for photolithographic applications - Towards understanding the relationship between chemical structure of polymer resin and lithographic performances. Adv. Mater. 2009, 21, 1121-1125.

45. Shirai, M.; Manabe, M.; Tsuji, S.; Itani, T. Epoxy-containing ArF resists with narrow molecular weight distribution. J. Vac. Sci. Tech. B 2006, 24, 3021-3024.

46. Shirai, M.; Sakai, K.; Koyanagi, T. Synthesis and dissolution properties of ArF resist with well-defined structure. J. Photopolym. Sci. Technol. 2005, 18, 389-392.

47. Matyjaszewski, K. Atom transfer radical polymerization (ATRP): Current status and future perspectives. Macromolecules 2012, 45, 4015-4039.

48. Munirasu, S.; Deshpande, A.; Baskaran, D. Hydrated clay for catalyst removal in copper mediated atom transfer radical polymerization(a). Macromol. Rapid Commun. 2008, 29, 1538-1543.

49. Fujimura, S.; Yano, H. Heavy-metal contamination from resists during plasma stripping. J. Electrochem. Soc. 1988, 135, 1195-1201.

50. Joubert, O.; Mathiot, D.; Pelletier, J. Metallic contamination in silicon during plasma resist stripping: A deep level transient spectroscopy study. Appl. Phys. Lett. 1989, 54, 2241-2243.

51. Olness, G.; Bernasek, S.; Gordon, M.; Chung, B.; Draper, C. Investigation of the gas-phase effluents and surface residuals of ozone ashed photoresists. Mat. Res. Soc. Proc. 1993, 315, 261-266.

52. Lawing, A.S. Gas-Phase Cleaning of Silicon Wafer Surfaces. Ph.D. Thesis, Massachusetts Institute of Technology, Cambridge, MA, USA, September 1997.

53. Allen, R.D.; Wan, I.Y.; Wallraff, G.M.; DiPietro, R.A.; Hofer, D.C.; Kunz, R.R. Design considerations for 193-nm positive resists. Microelectron. Technol. 1995, 614, 255-270. 
54. Nozaki, K.; Yano, E. High-performance resist materials for ArF excimer laser and electron beam lithography. Fujitsu Sci. Tech. J. 2002, 38, 3-12.

55. Nozaki, K.; Watanabe, K.; Namiki, T.; Igarashi, M.; Kuramitsu, Y.; Yano, E. A new single-layer resist for 193-nm lithography. Jpn. J. Appl. Phys. 1996, 35, L528-L530.

56. Gokan, H.; Esho, S.; Ohnishi, Y. Dry etch resistance of organic materials. J. Electrochem. Soc. 1983, 130, 143-146.

57. Maeda, K.; Nakano, K.; Iwasa, S.; Hasegawa, E. ArF chemically amplified positive resist based on alicyclic lactone polymer. Jpn. J. Appl. Phys. 2001, 40, 7162-7165.

58. Kamon, Y.; Momose, H.; Kuwano, H.; Fujiwara, T.; Fujimoto, M. Newly developed acrylic copolymers for ArF photoresist. In Proceedings of the Advances in Resist Technology and Processing XIX, Santa Clara, CA, USA, 15 July 2002; Volume 4690, pp. 615-622.

59. Ushirogouchi, T.; Asakawa, K.; Shida, N.; Okino, T.; Saito, S.; Funaki, Y.; Takaragi, A.; Tsutsumi, K.; Nakano, T. Advanced materials for 193-nm resists. In Proceedings of the Advances in Resist. Technology and Processing Xvii, Pts 1 and 2, Santa Clara, CA, USA, 23 June 2000; Volume 3999, pp. 1147-1156.

60. Becer, C.R.; Kokado, K.; Weber, C.; Can, A.; Chujo, Y.; Schubert, U.S. Metal-free synthesis of responsive polymers: Cloud point tuning by controlled “click” reaction. J. Polym. Sci. Polym. Chem. 2010, 48, 1278-1286.

61. Nowakowska, M.; Zapotoczny, S.; Karewicz, A. Synthesis of poly(sodium styrenesulfonate-block-vinylnaphthalene) by nitroxide-mediated free radical polymerization. Macromolecules 2000, 33, 7345-7348.

62. Lessard, B.; Maric, M. Incorporating glycidyl methacrylate into block copolymers using poly(methacrylate-ran-styrene) macroinitiators synthesized by nitroxide-mediated polymerization. J. Polym. Sci. Polym. Chem. 2009, 47, 2574-2588.

63. Greszta, D.; Matyjaszewski, K. Mechanism of controlled/“living” radical polymerization of styrene in the presence of nitroxyl radicals. Kinetics and simulations. Macromolecules 1996, 29, 7661-7670.

64. Coppola, G.; Bianchi, U.; Pallesi, B.; Fabbri, P. Salt effect on gel-permeation chromatography of partially charged polymers. J. Appl. Polym. Sci. 1972, 16, 2829-2834.

65. Cha, C.Y. Molecular weight distribution of polyacrylonitrile carrying pendant sulfonate groups. J. Polym. Sci. Polym. Lett. 1969, 7, 343-348.

66. Chiang, R.; Stauffer, J.C. Association of polyacrylonitrile prepared by low-temperature solution polymerization with an organometallic catalyst. J. Polym. Sci. A 1967, 5, 101-112.

67. Hann, N.D. Effects of lithium bromide on gel-permeation chromatography of polyester-based polyurethanes in dimethylformamide. J. Polym. Sci. Polym. Chem. 1977, 15, 1331-1339.

68. Reichmanis, E.; Houlihan, F.M.; Nalamasu, O.; Neenan, T.X. Chemical amplification mechanisms for microlithography. Chem. Mater. 1991, 3, 394-407.

69. Zumsteg, F.C.; Leffew, K.W.; Feiring, A.E.; Crawford, M.K.; Farnham, W.B.; Petrov, V.A.; Schadt, F.L.; Tran, H.V. The impact of fluoropolymers on line edge roughness in $193 \mathrm{~mm}$ imaging. J. Photopolym. Sci. Technol. 2005, 18, 467-469.

70. Feiring, A.E.; Crawford, M.K.; Farnham, W.B.; Feldman, J.; French, R.H.; Leffew, K.W.; Petrov, V.A.; Schadt, F.L.; Wheland, R.C.; Zumsteg, F.C. Design of very transparent fluoropolymer resists for semiconductor manufacture at $157 \mathrm{~nm}$. J. Fluor. Chem. 2003, 122, 11-16. 
71. Feiring, A.E.; Crawford, M.K.; Farnham, W.B.; Feldman, J.; French, R.H.; Junk, C.P.; Leffew, K.W.; Petrov, V.A.; Qiu, W.M.; Schadt, F.L.; et al. New amorphous fluoropolymers of tetrafluoroethylene with fluorinated and non-fluorinated tricyclononenes. Semiconductor photoresists for imaging at 157 and $193 \mathrm{~nm}$. Macromolecules 2006, 39, 3252-3261.

72. French, R.H.; Wheland, R.C.; Qiu, W.M.; Lemon, M.F.; Zhang, E.; Gordon, J.; Petrov, V.A.; Cherstkov, V.F.; Delaygina, N.I. Novel hydrofluorocarbon polymers for use as pellicles in $157 \mathrm{~nm}$ semiconductor photolithography: fundamentals of transparency. J. Fluor. Chem. 2003, 122, 63-80.

73. Takebe, Y.; Sasaki, T.; Shirota, N.; Yokokoji, O. Development of new resist materials for 193-nm dry and immersion lithography. Microelectron. Eng. 2006, 83, 1091-1093.

74. Lee, S.H.; Kim, J.W.; Kim, J.W.; Oh, S.K.; Park, C.S.; Lee, J.Y.; Kim, S.S.; Lee, J.W.; Kim, D.; Kim, J.; et al. Polymer structure modifications for immersion leaching control. In Proceedings of the Advances in Resist Materials and Processing Technology XXIV, San Jose, CA, USA, 23 March 2007; Volume 6519.

75. Lee, J.W.; Oh, S.K.; Kim, J.W.; Lee, S.H.; Jeong, Y.H.; Kim, S.S.; Park, M.H.; Kim, D.; Kima, J.; Lee, G.; et al. Polymer structure modifications for immersion leaching and watermark control. In Proceedings of the Advances in Resist Technology and Processing XXIII, Pts 1 and 2, San Jose, CA, USA, 11 April 2006; Volume 6153, pp. U756-U763.

76. Okoroanyanwu, U.; Shimokawa, T.; Byers, J.D.; Willson, C.G. Pd(II)-catalyzed addition polymerization and ring opening metathesis polymerization of alicyclic monomers: Routes to new matrix resins for $193 \mathrm{~nm}$ photolithography. J. Mol. Catal. A. Chem. 1998, 133, 93-114.

77. Okoroanyanwu, U.; Byers, J.; Shimokawa, T.; Willson, C.G. Alicyclic polymers for $193 \mathrm{~nm}$ resist applications: Lithographic evaluation. Chem. Mater. 1998, 10, 3328-3333.

78. Kim, J.B.; Lee, B.W.; Kang, J.S.; Seo, D.C.; Roh, C.H. Poly(t-butyl-3 alpha-(5-norbomene-2-carbonyloxy)-7 alpha,12 alpha-dihydroxy-5 beta-cholan-24-oate-co-maleic anhydride) for a 193-nm photoresist. Polymer 1999, 40, 7423-7426.

79. Kim, J.B.; Lee, J.J. Synthesis and characterization of norbomene-based polymers with 7,7-dimethyloxepan-2-one acid labile groups for chemically amplified photoresists. Polymer 2002, 43, 1963-1967.

(C) 2014 by the authors; licensee MDPI, Basel, Switzerland. This article is an open access article distributed under the terms and conditions of the Creative Commons Attribution license (http://creativecommons.org/licenses/by/3.0/). 